\title{
PASSENGER CIRCULATION PATTERNS AT INTERNASIONAL FERRY PORTS POLA SIRKULASI PENUMPANG DI PELABUHAN FERRY INTERNASIONAL
}

\author{
Tasya Amartha Amalia ${ }^{1)}$, Adi Sasmito ${ }^{2)}$, Anityas Dian Susanti ${ }^{3)}$ \\ Program Studi Arsitektur, Fakultas Teknik, Universitas Pandanaran \\ tasyaamarthaamalia@gmail.com \\ sasmitoadi308@gmail.com \\ anityass@yahoo.com
}

\begin{abstract}
Abstrak
Keberhasilan pengembangan wilayah di daerah kepulauan atau gugus - gugus pulau bergantung oleh peran transportasi sebagai urat nadi kehidupan. Bagi sebuah wilayah kepulauan, transportasi laut merupakan sarana transportasi yang paling efektif karena luas wilayah yang didominasi lautan sehingga mempunyai peranan yang penting dalam menjamin terselenggaranya mobilitas penduduk, barang dan jasa. Pelabuhan juga menjadi simpul penting dalam arus perdagangan dan distribusi barang di Indonesia maupun di dunia. Pelabuhan penumpang berperan sebagai prasarana transportasi moda trasportasinya bermuatan manusia (penumpang). Maksud dan tujuan dari penulis ini untuk mendapatkan pengetahuan tentang Pola Sirkulasi Penumpang di Pelabuhan Ferry Internasional. Suatu Pelabuhan.penumpang.umumnya dilengkapi dengan terminal penumpang sebagai stasiun yang melayani berbagai aktivitas yang berhubungan dengan kebutuhan orang yang berpergian, seperti kantor imigrasi, administrasi pelabuhan, dan kantor maskapai pelayaran. Pola sirkulasi yang dapat digunakan yaitu Pola Sirkulasi Curvelinear.

Kata kunci: Pola sirkulasi, Pelabuhan ferry internasional, Pelabuhan.
\end{abstract}

\begin{abstract}
The success of regional development in islands or island groups depends on the role of transportation as the lifeblood of life. For an archipelagic region, sea transportation is the most effective means of transportation because the area is dominated by the ocean so that it has an important role in ensuring the mobility of people, goods and services. The port is also an important node in the flow of trade and distribution of goods in Indonesia and in the world. The passenger port plays a role as a transportation infrastructure with human (passenger) modes of transportation. The intent and purpose of this writer is to gain knowledge about the Passenger Circulation Pattern at the International Ferry Port. A passenger port is generally equipped with a passenger terminal as a station that serves various activities related to the needs of travelers, such as immigration offices, port administrations, and shipping airline offices. The circulation pattern that can be used is the Curvelinear Circulation Pattern.

Keywords: Circulation patterns, Internasional Ferry Ports, Ports.
\end{abstract}

\section{PENDAHULUAN}

Keberhasilan pengembangan wilayah di daerah kepulauan atau gugus gugus pulau sangat dipengaruhi oleh peran transportasi sebagai urat nadi kehidupan. Pelabuhan diartikan sebagai tempat yang terdiri atas daratandan/atau peraira $\mathrm{n}$ dengan batas-batas tertentu sebagai tempat berkegiatan pemerintah dan kegiatan pengusahaan yang 
dipergunaka $\mathrm{n}$ sebagai tempat kapal berlabuh, naik turun penumpang dan/atau bongkar mua $t$ barang, berupa terminal dan tempat berlabuh kapal yang dilengkapi dengan fasilitas keselamatan dan keamanan pela yaran dan kegiatan penunjang pelabuhan serta sebagai tempat perpindahan intra dan antarmoda transportasi.

Pelabuhan penumpang umumnya dilengkapi dengan terminal penumpang sebagai stasiun yang melayani berbagai aktivitas yang berhubungan dengan kebutuhan orang yang berpergian,seperti kantor imigrasi, administrasi pelabuhan, dan kantor maskapai pelayaran. System transportasi yang andal, berkemampuan tinggi, serta berkualitas akan memberikan pelayanan transportasi yang lancar, aman, nyaman, selamat, berkapasitas, tertib, teratur, dan murah sehingga memberikan dampak positif terhadap pembangunan di daerah yang relative tinggi, terisolisir, terpencil, serta terletak di daerah perbatasan.

\section{TINJAUAN TEORI}

\section{Pengertian pelabuhan}

Pelabuhan mula-mula mempunyai arti yang sempit, yaitu suatu perairan yang terlindung sebagai tempat berlabuh-nya kapal-kapal dengan.aman.dengan cara membuang sauh.Harbour adalah perairan. yang terlindung, tempat kapal- kapal berlindung dengan aman, dengan sauh atau mengikat dengan pelampung. Port adalah pintu gerbang atau tempat yang mempunyai harbour lengkap dengan petugas bea cukai. Dock adalah suatu kolam dengan pintu air tempat dimana kapal membongkar muat atau keperluan perbaikan.

Pelabuhan adalah tempat berlabuh dan atau tempat bertambahnya kapal laut serta kendaraan lainnya, menaikkan dan menurunkan penumpang, bongkar muat barang dan hewan serta merupakan daerah lingkungan kerja kegiatan ekonomi.

\section{Jenis-jenis terminal pelabuhan}

a. Terminal Barang Potongan (General Cargo Terminal), merupakan terminal barang yang memerlukan perlakuan khusus dalam pengangkutannya.

b. Terminal Barang Curah (Bulk Cargo Terminal) merupakan terminal.untuk barang lepas atau tidak dikemas yang cara memasukkannya dituang atau dipompa ke dalam kapal.

c. Terminal Peti Kemas (Container Terminal) merupakan terminal untuk barang-barang yang dimasukkan ke dalam peti kemas.

d. Terminal Penumpang

(Passenger Terminal) merupakan terminal yang digunakan untuk menaikkan dan menurunkan penumpang. "Terminal penumpang merupakan titik atau tempat perpindahan penumpang embarkasi dari transportasi darat ke transportasi laut dan perpindahan penumpang debarkasi dari transportasi laut ke transportasi darat" (Moedjiono,2003:96)

\section{Pemakai dan aktivitas penumpang pelabuhan}

Menurut Moedjiono (2003: 96) pemakai terminal penumpang kapal dapat dikelompokkan menjadi tiga yaitu:

a. Penumpang Embarkasi atau keberangkatan adalah penumpang yang akan berangkat menggunakan transportasi laut. Terdiri dari penumpang dalam negeri (penumpang antar pulau, transmigrasi, dan wisata) dan penumpang samudera (turis).

b. Penumpang Debarkasi atau Kedatangan adalah penumpang yang datang di tujuan, mulai turun dari kapal sampai keluar dari terminal penumpangn. Meliputi penumpang dalam negeri dan penumpang samudera (turis).

c. Pengelola adalah orang-orang yang melayani penumpang, pengantar, dan penjemput di terminal penumpang. 
Meliputi petugas administrasi dan operasional.

d. Pengunjung merupakan orang orang yang mengantar ataupun menjemput tamu-tamu terminal penumpang kapal laut.

\section{Pola sirkulasi}

Menurut Francis D.K Ching dalam bukunya Teori Arsitektur (1993), alur sirkulasi dapat diartikan sebagai "tali" yang mengikat ruang-ruang suatu bangunan atau suatu deretan ruang-ruang dalam maupun luar, menjadi saling berhubungan. Oleh karena itu kita bergerak dalam waktu melalui suatu tahapan ruang. Kita merasakan ruang ketika kita menetapkan tempat tujuan.

\section{Jenis-jenis sirkulasi}

Menurut Logi Tofani (2011) pada dasarnya sirkulasi terbagi menjadi 3 berdasarkan fungsinya, yaitu:

\section{Sirkulasi Manusia}

"Pergerakan manusia akan mempengaruhi system sirkulasi dalam tapak sirkulasi manusia dapat berupa pedestrian atau plaza yang membentuk.hubungan erat dengan aktivitas kegiatan di dalam tapak. Hal yang perlu diperhatikan antara lain lebar jalan, pola lantai, kejelasan orientasi, lampu jalan, dan fasilitas penyeberangan" ( Hari , 2009). "Selain.itu ada beberapa ciri dari sirkulasi manusia, yaitu: a) kelonggaran dan fleksibel dalam bergerak, b) berkecepatan rendah, dan c) sesuai dengan skala manusia" (Tofani, 2011).

2. Sirkulasi Kendaraan

Menurut Aditya Haril (2008) mengungkapkan bahwa secara

hierarki sirkulasi kendaraan dapat dibagi menjadi 2 jalur, yaitu: a) jalur distribusi yaitu jalur untuk gerak perpindahan lokasi (jalur cepat), dan b) jalur akses, jalur yang melayani hubungan jalan dengan pintu masuk bangunan.

3. Sirkulasi Barang
"Sirkulasi barang pada umumnya di satukan atau menumpang pada system sirkulasi lainnya. Namun, pada perancangan tapak dengan fungsi tertentu system sirkulasi barang menjadi sangat penting untuk diperhatikan. Contoh sistem sirkulasi barang secara horizontal dan vertikal adalah lift barang, conveyor belt, jalur troli, dan lain-lain." (Rahmah,2010).

\section{Bentuk pola sirkulasi}

a. Pola sirkulasi direct adalah pola sirkulasi yang mengarah langsung dan hanya memberi satu.pilihan ke tujuan akhir. Akses visual yang diterima oleh pengunjung adalah tujuan akhir ke ruang yang di tuju.

b. Pola sirkulasi curvelinear adalah garis linear yang berliku-liku halus dan memberi satu pilihan ke tujuan akhir. Pada pola sirkulasi ini akses visual ke tujuan akhir kurang jelas dan memiliki potensi untuk memberi kejutan - kejutan ruang.

c. Pola sirkulasi erractic adalah pola sirkulasi yang terpatah - patah. Akses visual ke tujuan akhir kurang jelas dan memiliki potensi untuk memberi kejutan - kejutan ruang.

d. Pola sirkulasi interrupted;adalah keadaan ruang sirkulasi yang terputus-putus pada bagian tertentu dan akses visual ke tujuan akhir kurang jelas.

e. Pola sirkulasi looping adalah pandangan ke arah tujuan akhir disamarkan dan memberi kesan mengalir apa adanya.

f. Pola sirkulasi distraction adalah bentuk sirkulasi dimana pandangan kearah yang di tuju dikacaukanf oleh obyek obyek lain Fokus visual mengalir bersama dengan waktu tempuh.

g. Pola sirkulasi obscure adalah pola sirkulasi dimana lalu lintas sirkulasi yang disembunyikan dari jangkauan umum.

h. Pola sirkulasi diverging adalah bentuk sirkulasi bercabang 
sehingga akses ke tujuan akhir secara fisik dan visual menjadi tidak jelas.

\section{METODE PENELITIAN Pendekatan penelitian}

Metode yang dilakukan adalah penelitian deskriptifrdengan pendekatan kualitatif. Pendekatan kualitatifrmenurut Sugiyono (2017:9) adalah metode penelitian yang berlandaskan filsafat postpositivisme, digunakan untuk meneliti pada kondisi obyek yang alamiah. Artinya data yang dikumpulkan buka berupa angka-angka, melainkan data tersebut berasal dari naskah wawancara, catatan lapangan, dokumen pribadi, catatan memo, dan dokumen resmi lainnya. Sehingga tujuannya adalah ingin menggambarkan realita yang terdapat dalam tapak sebagai suatu potensi pengembangan.

\section{Studi pustaka}

Studi pustaka merupakan langkah awal dalam metode pengumpulan data. Studi pustaka merupakan teknik pengumpulan data dengan melakukan penelaahan terhadap berbagai buku, literature, catatan, serta sebagai laporan yang berkaitan dengan masalah yang ingin dipecahkan ( Nazir, 1988). Maka dapat dikatakan bahwa studi pustaka dapat mempengaruhi kredibilitas hasil penelitian yang dilakukan.

\section{Studi kasus}

Objek dalam penelitian ini adalah faktor - faktor yang mempengaruhi pola sirkulasi penumpang, sedangkan subjek dalam penelitian ini adalah:

1. Pelabuhan Ferry Batam Centre di Kepulauan Riau.

2. Berjaya Waterfront Ferry Terminal di Malaysia.

3. HarbourFront Centre di Singapore.

\section{Teknik pengumpulan data}

Data penelitian ini menggunakan teknik pengumpulan data sebagai berikut:

1. Data primer

Observasi, wawancara, dan dokumentasi.

2. Teknik analisis data

Dalam penelitian ini, teknik analisa data yang digunakan adalah teknik analisa deskriptif dengan pendekatan kualitatif yaitu menjabarkan hasil penelitian sebagaimana adanya. 


\section{PEMBAHASAN}

Tabel 1. Analisa terhadap permasalahan berdasarkan data dan fakta

\begin{tabular}{|c|c|c|c|}
\hline & $\begin{array}{c}\text { Pelabuhan Batam } \\
\text { Centre }\end{array}$ & $\begin{array}{l}\text { Berjaya Water Front } \\
\text { Terminal Ferry }\end{array}$ & Harbour Front Centre \\
\hline \multicolumn{4}{|c|}{$\begin{array}{c}\text { Keberangkatan } \\
\text { (Departure) }\end{array}$} \\
\hline Sirkulasi & $\begin{array}{l}\text { In } \rightarrow \text { Ticketing } \rightarrow \\
\text { R. Tunggu lantai } 2 \\
\rightarrow \text { Boarding Pass } \\
\rightarrow \text { x-Ray } \rightarrow \text { Stamp } \\
\text { Passport } \\
\rightarrow \text { R. Tunggu } \rightarrow \text { Chek-in } \\
\text { Ticket } \rightarrow \text { ferry }\end{array}$ & $\begin{array}{l}\text { Mall } \rightarrow \text { Ticketing } \rightarrow \\
\text { Boarding pass } \rightarrow \text { Stamp } \\
\text { passport } \rightarrow \text { x- } \\
\text { Ray (Barang) } \rightarrow \text { R. } \\
\text { Tunggu } \rightarrow \text { chek-in } \\
\text { ticket } \rightarrow \text { Ferry }\end{array}$ & $\begin{array}{l}\text { Mall } \rightarrow \text { Ticketing (lantai } \\
3 \text { ) } \rightarrow \text { R. tunggu (lantai } 2 \text { ) } \\
\rightarrow \text { Boarding Pass } \rightarrow \text { finger } \\
\text { print passport } \rightarrow \text { x- } \\
\text { ray } \rightarrow \text { R.tunggu } \rightarrow \text { Check- } \\
\text { in ticket } \rightarrow \text { ferry }\end{array}$ \\
\hline \multicolumn{4}{|c|}{$\begin{array}{c}\text { Kedatangan } \\
\text { (Arrived) }\end{array}$} \\
\hline Sirkulasi & $\begin{array}{l}\text { Ferry }(\text { out }) \rightarrow \text { Stamp } \\
\text { passport } \rightarrow \text { x-Ray } \rightarrow \text { Out }\end{array}$ & $\begin{array}{l}\text { Ferry (out) } \rightarrow \text { Stamp } \\
\text { passport } \rightarrow \text { x-Ray(barang) } \\
\rightarrow \text { Out }\end{array}$ & $\begin{array}{l}\text { Ferry (out) } \rightarrow \text { stamp } \\
\text { passport } \rightarrow \mathrm{x}-\text { Ray } \rightarrow \text { Out }\end{array}$ \\
\hline \multirow[t]{2}{*}{$\begin{array}{l}\text { Kelebihan / } \\
\text { Kekurangan }\end{array}$} & $\begin{array}{l}\text { Kelebihan: } \\
\text { 1. Sirkulasi terarah } \\
\text { 2. } \\
\text { Alur jelas dan mudah } \\
\text { di pamahi. } \\
\text { 3. } \\
\text { Terdapat papan } \\
\text { penunjuk arah } \\
\text { (Signage) } \\
\text { 4. } \\
\text { Pintu utama untuk } \\
\text { memasuki pusat } \\
\text { perbelanjaan (mall) } \\
\text { berada di lantai } 3 \text { dan } \\
\text { menggunakan } \\
\text { jembatan penghubung } \\
\text { antar bangunan } \\
\text { pelabuhan ke mall. } \\
\text { 5. } \\
\text { Ticketing dalam } 1 \\
\text { ruangan yang besar } \\
\text { dan terdapat beberapa } \\
\text { loket. }\end{array}$ & $\begin{array}{l}\text { Kelebihan: } \\
\text { 1. Sirkulasi terarah } \\
\text { 2. Alur jelas dan mudah } \\
\text { di pahami } \\
\text { 3. Terdapat papan } \\
\text { penunjuk arah } \\
\text { (signage) mulai dari } \\
\text { masuk mall sampai ke } \\
\text { pelabuhan. Maupun } \\
\text { sebaliknya. }\end{array}$ & $\begin{array}{l}\text { Kelebihan: } \\
\text { 1. Sirkulasi terarah. } \\
\text { 2. Alur jelas dan mudah di } \\
\text { pahami. } \\
\text { 3. Terdapat papan } \\
\text { penunjuk arah (signage) } \\
\text { mulai dari masuk mall } \\
\text { sampai ke pelabuhan. } \\
\text { Maupun sebaliknya. } \\
\text { 4. Ticketing berada di } \\
\text { lantai } 3 \text { dengan banyak } \\
\text { loket. Sehingga } \\
\text { penumpang tidak perlu } \\
\text { berdesakan untuk } \\
\text { membeli ticket. } \\
\text { 5. Menggunakan Finger } \\
\text { print passport sehingga } \\
\text { tidak perlu mengantri. }\end{array}$ \\
\hline & $\begin{array}{l}\text { Kekurangan: } \\
\text { 1. Penumpang maupun } \\
\text { pengantar dapat } \\
\text { memasuki bangunan } \\
\text { melewati pintu keluar } \\
\text { dan masuk. Begitupula } \\
\text { sebaliknya, ketika } \\
\text { penumpang ingin } \\
\text { keluar bangunan dapat } \\
\text { mengakses kedua } \\
\text { pintu tersebut. Hal ini } \\
\text { dapat membuat } \\
\text { sirkulasi yang simpang } \\
\text { siur. Jika penumpang } \\
\text { rame (weekend and } \\
\text { Holiday) jalur menuju }\end{array}$ & $\begin{array}{l}\text { Kekurangan: } \\
\text { 1. Hanya memiliki satu } \\
\text { tempat Ticketing } \\
\text { sehingga membuat } \\
\text { penumpang mengantre } \\
\text { sangat panjang untuk } \\
\text { membeli ticket. } \\
\text { 2. Ruang tunggu untuk } \\
\text { keberangkatan sedikit } \\
\text { sempit sehingga jika } \\
\text { rame (weekend dan } \\
\text { holiday) membuat } \\
\text { penumpang } \\
\text { berdesakan. }\end{array}$ & Kekurangan: \\
\hline
\end{tabular}




\begin{tabular}{|l|l|l|l|}
\hline & ke Ferry yang di batasi & & \\
pagar besi setinggi 500 & & \\
m dapat di seberangi & & & \\
dengan jalur yang & akan masuk ke & & \\
bangunan. & & \\
\hline
\end{tabular}

Hasil kesimpulan dari tabel di atas yaitu sirkulasi penumpang dari ke tiga studi kasus sudah tertata dan di perlukan perlebaran ruangan atau sirkulasi yang memutar untuk mengantri agar tidak mengantri panjang satu baris atau dua baris saja. Karena di salah satu studi kasus sudah menerapkan perlebaran ruangan dan sirkulasi yang memutar untuk mengantri sehingga tidak perlu berdesakan.

1. Pelabuhan Batam Centre

Analisa pola sirkulasi pengunjung.

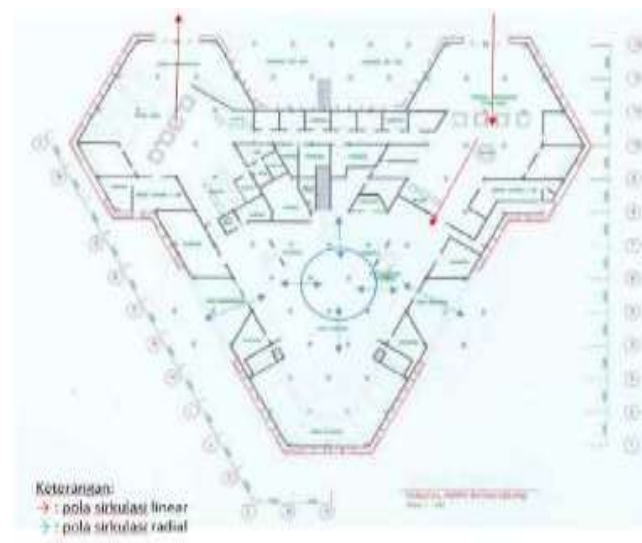

Gambar 1. Pola sirkulasi denah lantai 1

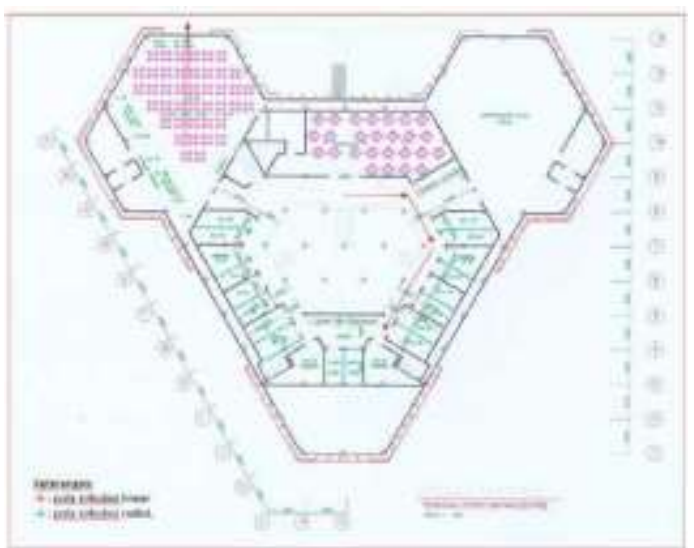

Gambar 2. Pola sirkulasi denah lantai 2

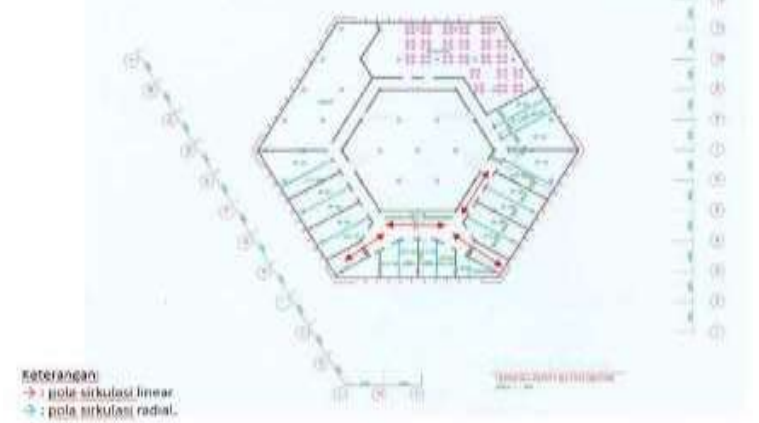

Gambar 3. Pola sirkulasi denah lantai 3

Menurut penelitian dan hasil analisa data yang telah dilakukan ada dua pola sirkulasi yang digunakan, yaitu pola sirkulasi linier dan pola sirkulasi radial.

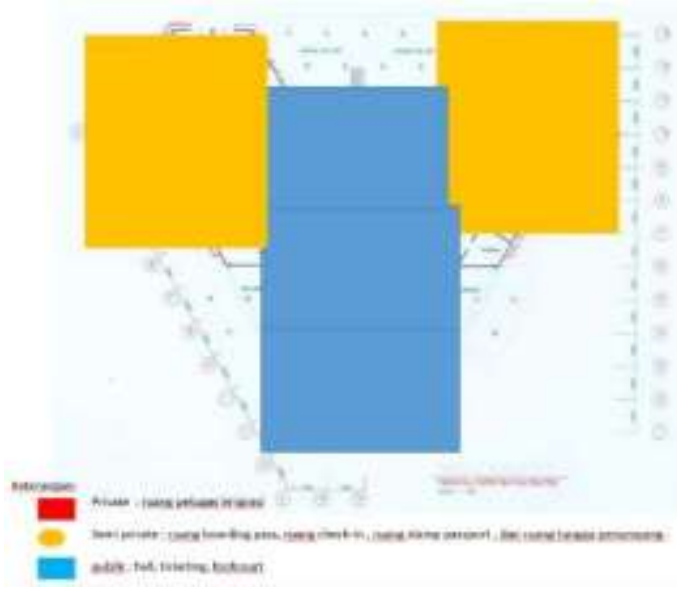

Gambar 4. Zonasi denah lantai 1

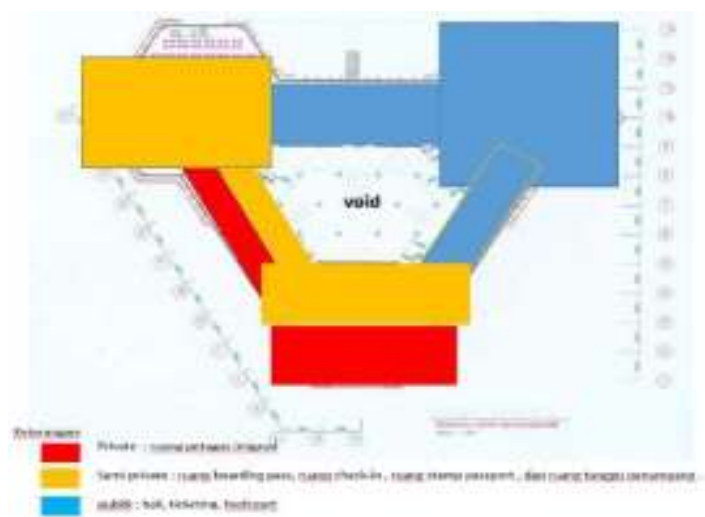

Gambar 5. Zonasi denah lantai 2 
Gambar 9. Zoning lantai 1

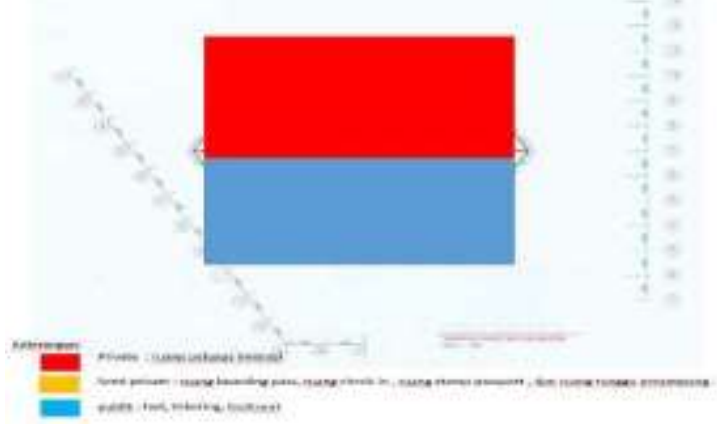

Gambar 6. Zonasi denah lantai 3

\section{Harbour Front}

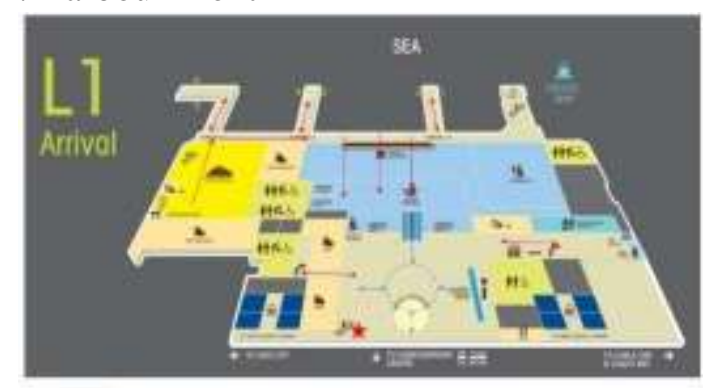

IIx-

Gambar 7. Pola sirkulasi lantai

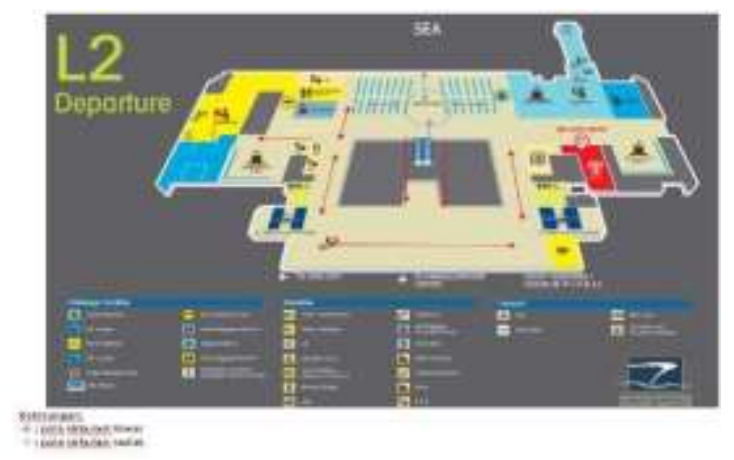

Gambar 8. Pola sirkulasi lantai 2

Menurut penelitian dan hasil analisa data yang telah dilakukan ada dua pola sirkulasi yang digunakan, yaitu pola sirkulasi linier dan pola sirkulasi radial.
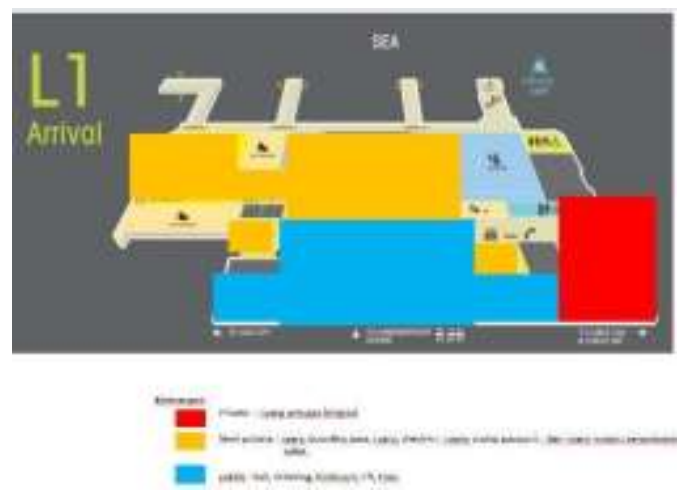

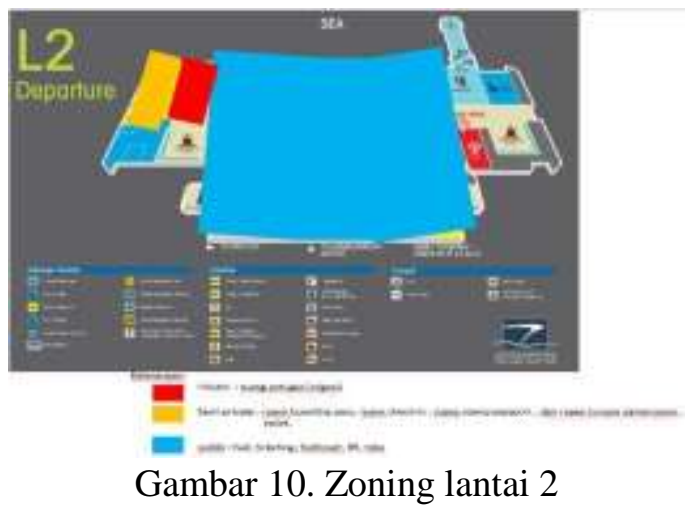

5. KESIMPULAN

Dari penelitian mengenai pola sirkulasi ketiga studi kasus pelabuhan ferry internasional yaitu Pelabuhan Batam Centre (Batam, Kepulauan Riau), Berjaya Waterfront Terminal Ferry (Johor Bahru, Malaysia), dan HarbourFront Centre ( Singapore), dapat diperoleh kesimpulan sebagai berikut:

1. Pola sirkulasi penumpang dalam tiga studi kasus ini sudah memenuhi beberapa kriteria seperti lebar jalan penumpang, kejelasan orientasi, lampu dan kefleskibelan dalam bergerak . menggunakan Pola sirkulasi curvelinear adalah garis linear yang berliku-liku halus dan memberi satu pilihan ke tujuan akhir dan hubungan antar ruang yaitu Pass Trough Spaces

2. Dengan adanya Pusat Perbelanjaan (Mall) di pelabuhan dapat menambah daya tarik penumpang maupun pengunjung.

3. Adanya Pemisahan penumpang yang keluar bangunan dan masuk bangunan dapat mencegah tubrukan antar penumpang .

4. Selain memberikan kenyamanan pada pengunjung yang memiliki kondisi fisik normal, masing masing pelabuhan menggunakan lift untuk memudahkan pengunjung difabel untuk mengakses pelabuhan dengan mudah dan nyaman. 
5. Pelabuhan menggunakan penanda (Signage) untuk menunjukkan arah dan fasilitas-fasilitas yang ada di pelabuhan sehingga memudahkan dan memberikan kenyamanan sirkulasi bagi para penumpang untuk mengakses fasilitas tersebut.

\section{DAFTAR PUSTAKA}

Honggo Wijoyo .Terminal Penumpang Kapal Laut Pelabuhan Harbour Bay Pulau Batam Pius.

Rohana veramyta. Perpustakaan Anak Sebagai Sarana Sendukung Tumbuh Kembang Anak di Kota Yogyakarta.

Anonim. 1 April 2018. Jurnal Transportasi.

Anonim. 2017. JURNAL eDIMENSI ARSITEKTUR.

Anonim. 2019. "MARINA" Sosial Ekonomi Kelautan dan Perikanan.

Nyoman Budiartha Raka Mandi. Perencanaan dan perancangan konstruksi bangunan laut dan pantai.

Anonim. Terminal Penumpang Pelabuhan Ferry Ambarita, Samosir

Anonim. April 2014. Jurnal Reka Karsa

CTeknik Arsitektur Itenas.

Dedy Arianto. 2017. Jurnal Penelitian Transportasi Laut. 